\title{
Urinary EN-2 to predict prostate cancer: Systematic review and meta-analysis
}

\author{
Maria Inês da Rosa ${ }^{1,2,3 *}$, Eduardo Ronconi Dondossola ${ }^{1}$, Maria Cecilia Manenti Alexandre ${ }^{1}$, Kristian Madeira $^{1}$, \\ Florentino de Araújo Cardoso ${ }^{4}$, Antonio José Grande ${ }^{1,2}$

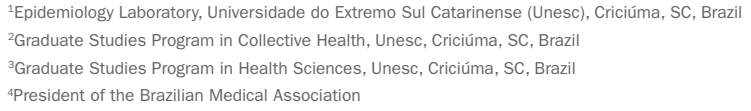

Study conducted at Laboratory of Epidemiology, Universidade do Extremo Sul Catarinense (Unesc),

Criciúma, Sc, Brazil

Article received: $12 / 9 / 2016$ Accepted for publication: $12 / 19 / 2016$

*Correspondence: Address: Rua Cruz e Souza, 510 Criciúma, SC - Brazil Postal code: $88811-550$ mir@unesc.net

\section{SUMmARY}

Introduction: Prostate cancer is the second type of cancer diagnosed and the fifth cause of death in men worldwide. Early diagnosis helps to control disease progression. Currently, prostate specific antigen is the standard biomarker, as it has a broad scope of identification and, thus, new and more specific biomarkers must be studied.

Objective: To evaluate the accuracy of engrailed-2 protein (EN2) in urine as a prostate cancer biomarker.

Method: A comprehensive search was conducted in the period from January 2005 to July 2016 using the following electronic databases: Medline (PubMed), Embase, Cochrane Library and Lilacs. The keywords used in the databases were: "engrailed-2," "EN2," "prostatic neoplasms." The search was limited to humans and there was no language restriction. Critical appraisal of the included studies was performed according to Quadas-2. Statistical analysis was performed using Meta-DiSc ${ }^{\circledR}$ and RevMan 5.3 softwares.

Results: A total of 248 studies were identified. After title and abstract screening, 231 studies were removed. A total of 17 studies were read in full and two studies were included in the meta-analysis. The pooled sensitivity was 66\% (95CI 0.56-0.75) and specificity was $89 \%$ (95CI 0.86-0.92). The DOR was 15.08 (95CI 8.43-26.97). Conclusion: The EN2 test showed high specificity (89\%) and low sensitivity (66\%).

Keywords: prostatic neoplasms, biomarker, EN2, systematic review, meta-analysis.

\section{INTRODUCTION}

Prostate cancer $(\mathrm{PCa})$ is the fifth most frequent type of cancer in the world and the second most diagnosed noncutaneous cancer in men in the United States according to the International Agency for Cancer Research. ${ }^{1}$

The disease has good prognosis when diagnosed at an early stage, since it is responsive to various treatments. Patients diagnosed with PCa at stage I, II, or III have a high 5-year survival rate; however, patients with stage IV cancer have a low 5 -year survival rate of $<27 \%$, highlighting the importance of early detection. ${ }^{2}$

Early stage PCa is often asymptomatic and the gold standard test is prostate biopsy, which is usually indicated in case of one or more of the following factors: family history, abnormal lumps within the prostate by phys- ical digital rectal examination, or an elevated serum prostate-specific antigen (PSA). ${ }^{3}$

PSA started to be used 30 years ago, and it is the most common biomarker to diagnose and manage PCa. Despite being used globally, it is important to mention that the blood levels of PSA are often high in men with prostatic benign conditions as well. ${ }^{4}$

A recent systematic review of randomized controlled trials of PSA screening for PCa concluded that screening did not significantly decrease PCa-specific or overall mortality, and showed that PSA can result in a high number of false-positives, leading to overdiagnosis and overtreatment. ${ }^{5}$ Low specificity of PSA and unnecessary biopsies are the most common problems of balancing benefits and risks in tests. ${ }^{6}$ 
Recently, engrailed-2 (EN2), a protein found in the urine of patients with $\mathrm{PCa}$, proved to be a potential biomarker for the diagnosis of PCa compared to ELISA. ${ }^{7}$

The identification of cancer biomarkers that can be measured in a noninvasive way should improve the specificity of PSA in the detection of PCa. Thus, we performed a systematic review and meta-analysis to verify the accuracy of EN2 as a potential biomarker of PCa.

\section{Method}

\section{Data sources and searches}

The study protocol was registered at PROSPERO 35417 and included a systematic review according to protocol and PRISMA-statement guidelines. ${ }^{8}$

We searched the Medline (PubMed), Embase, Cochrane Central Register of Controlled Trials, Ibecs, Biosis, Web of Science, Scopus, Conference Abstracts and Grey Literature (Google Scholar; British Library) databases from January 2005 to July 2016. We used the following terms, both as text words, Medical Subjects Heading $(\mathrm{MeSH})$ or equivalent subject heading/thesaurus terms: "Prostate cancer" and "prostatic neoplasms." These terms were combined with "engrailed-2." The search had no language restrictions. The reference list of all available primary studies was reviewed to identify additional relevant studies. A copy of the complete search strategy is available on request.

For this review, we used the definitions: Index test The diagnostic test consisted of the urine EN2 analysis and Reference standard - The diagnostic reference was the result of the histological analysis of standard paraffin-embedded sections.

The inclusion criteria for this systematic review were: studies measuring EN2 levels in at least two histological diagnoses comparing with PCa, benign or normal prostate tissue.

\section{Study selection}

The abstracts/titles identified from the search were screened by two reviewers (E.R.D. and M.C.M.A.). Disagreements about the inclusion or exclusion of studies were resolved by consensus, and, if consensus was not possible, disagreements were resolved by a third reviewer (M.I.R). The final inclusion or exclusion of a study was made with a standard checklist. We included case-control and cohort studies, both prospective and retrospective.

\section{Data extraction and quality assessment}

We extracted data in duplicate (E.R.D. and M.C.M.A) with a standard form. We extracted information about study design, participants' description, index test description, reference test description, and total number of participants. A $2 \times 2$ table was created for each study comparing EN2 levels and the histologic diagnosis.

The eligibility criteria of all articles were assessed using Quality Assessment of Diagnostic Accuracy Studies (Quadas-2). This tool comprises four domains: patient selection, index test, reference standard, and flow and timing. Each domain is assessed in terms of the risk of bias, and the first three domains are also assessed in terms of concerns regarding applicability. Signaling questions are included to help judge the risk of bias. ${ }^{9}$ The quality assessment of the studies was independently performed by two authors (E.R.D. and M.C.M.A). Any disagreement was resolved by consensus.

\section{Data synthesis and statistical analysis}

For each study, $2 \times 2$ contingency tables were constructed so that all cases were classified as PCa or benign lesions. We calculated the true-positive rate (TPR; sensitivity), specificity, and false-positive rate (FPR; 1 - specificity). Bivariate analysis was used to calculate the pooled estimates of sensitivity, and specificity with $95 \%$ confidence intervals (95CI) for the summary estimates. ${ }^{10}$ The diagnostic odds ratio (DOR) can relate to different combinations of sensitivity and specificity. The DOR describes the odds of positive test results in participants with disease compared with the odds of positive test results in those without disease.

Statistical analysis was performed using Meta-DiSc ${ }^{\circledR}$ (Clinical Biostatistics Unit, Ramón y Cajal Hospital, Madrid, Spain) (version 1.4) and RevMan 5.3 software. ${ }^{11,12}$

\section{Results}

The searches identified a total of 248 studies, of which 17 were potentially relevant after initial assessment. Of these, 15 full-text studies were excluded. Two primary studies (Morgan et al. and Killick et al.) ${ }^{7,13}$ involving 597 participants met the criteria for inclusion and were analyzed (Figure 1).

The main characteristics of the included studies are shown in Table 1. Both were conducted in the UK and used ELISA assay for diagnosis.

\section{Methodological quality of included studies}

The risk of bias for patient selection, index test, reference standard, flow and timing, as well as the concerns for applicability related to the first three domains, are shown in Figure 2. The Quadas-2 items for Morgan study had low risk of bias in all domains. The second study by 
TABLE 1 Characteristics of primary diagnostic studies on prostate cancer measuring urinary levels of EN2.

\begin{tabular}{|c|c|c|c|c|c|c|c|c|c|c|c|c|}
\hline $\begin{array}{l}\text { Author/ } \\
\text { Year }\end{array}$ & Mean age & $\begin{array}{l}\text { Age } \\
\text { control }\end{array}$ & $\begin{array}{l}\text { Design and } \\
\text { settings }\end{array}$ & $\begin{array}{l}\mathrm{N} \\
\text { Control }\end{array}$ & N PCa & $\begin{array}{l}\text { Sensibility } \\
(\%)\end{array}$ & $\begin{array}{l}\text { Specificity } \\
(\%)\end{array}$ & TP & FP & FN & $\mathrm{TN}$ & $\begin{array}{l}\text { EN2 cut-off } \\
(\mu g / L)\end{array}$ \\
\hline $\begin{array}{l}\text { Morgan } \\
\text { et al. }{ }^{7}\end{array}$ & $67(44-83)$ & $63(42-86)$ & Case-control & 102 & 82 & 66 & 88.2 & 54 & 12 & 28 & 90 & 42.5 \\
\hline Killick et al. ${ }^{13}$ & $53(40-69)$ & $\begin{array}{l}54.3 \\
(40-69)\end{array}$ & Cross-sectional & 392 & 21 & 66.7 & 89.3 & 14 & 42 & 7 & 350 & 42.5 \\
\hline
\end{tabular}

PCa: prostate cancer; TP: true positive; FP: false positive; FN: false negative; TN: true negative.

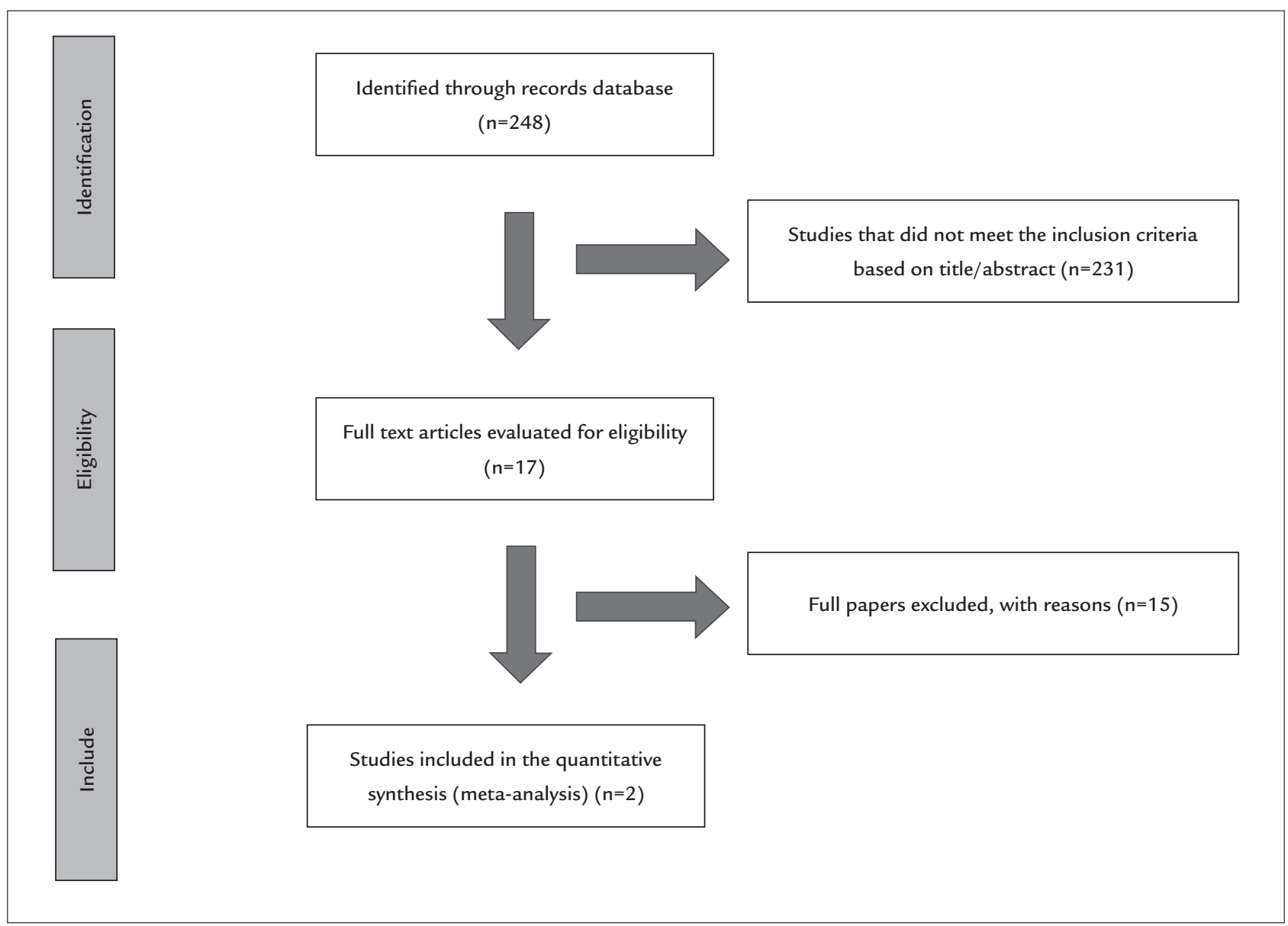

FIGURE 1 Flow diagram of the study selection process.

Killick et al. ${ }^{13}$ showed unclear risk of bias to the reference standard (prostate biopsy), since it is unclear whether all participants underwent prostate biopsy, flow and time (patient flow and time between the completion of the EN2 test and biopsy). These criteria resulted in a high risk of bias for the reference standard, with respect to applicability criteria.

\section{EN2 test vs. biopsy}

The two studies had a combined sensitivity (Figure 3A) of $66 \%$ (95CI 56-75) and a combined specificity (Figure
3B) of 89\% (95CI 86-92). The DOR (Figure 3C) was 15.082 (95CI 8.432-26.977).

Begg's funnel plot and Egger's test were not performed to assess the publication bias of the literature in all comparison models since only two studies were included.

\section{Discussion}

PCa is becoming a public health concern worldwide and PSA test is not being recommended by its own creator, Professor Richard J. Ablin, who always say "PSA testing cannot detect prostate cancer." This is the first systematic review 


\section{Risk of bias}

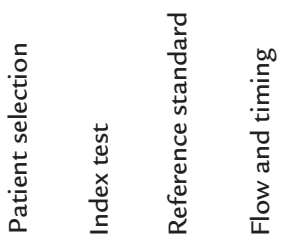

Killick et al. ${ }^{13}$

Morgan et al. ${ }^{7}$

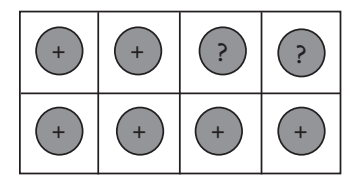

Applicability concerns
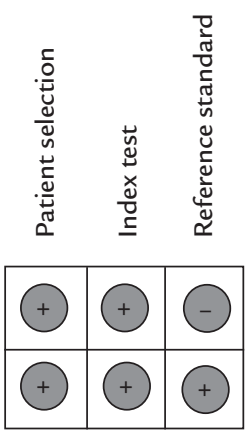

FIGURE 2 Results of the evaluation of each study according to Quadas-2.

A

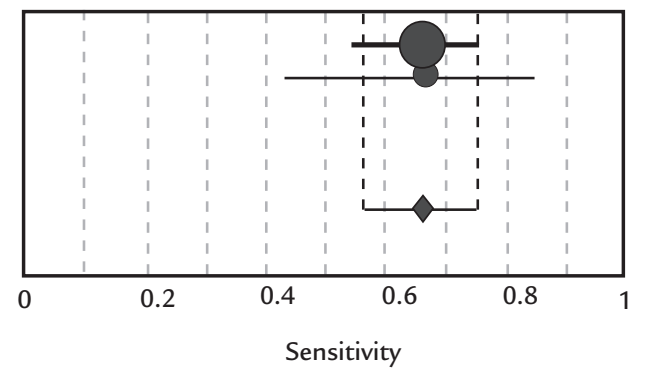

B

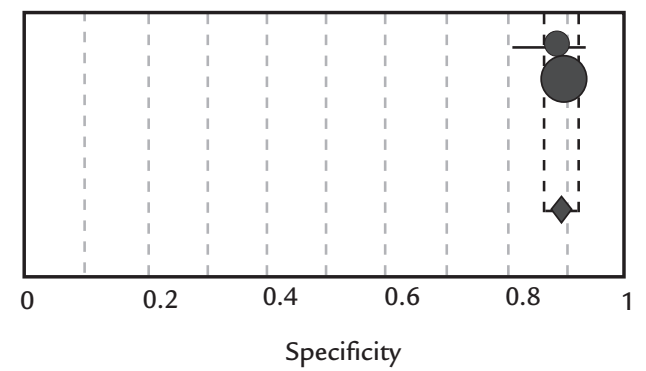

C

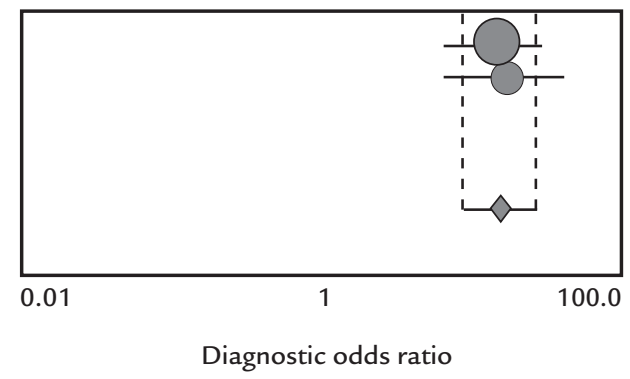

Morgan et al. ${ }^{7}$ Killick et al. ${ }^{13}$

Pooled sensitivity $=0.66(0.56$ to 0.75$)$

Chi-square $=0.00 ; \mathrm{df}=1 \quad(\mathrm{p}=0.9440)$

Inconsistency (I-square) $=0.0 \%$

Morgan et al. ${ }^{7}$

Killick et al. ${ }^{13}$

Specificity $(95 \mathrm{Cl})$

$0.88(0.80-0.94)$

$0.89(0.86-0.92)$

Pooled specificity $=0.89$ (0.86 to 0.92$)$

Chi-square $=0.09 ; \mathrm{df}=1 \quad(p=0.7638)$

Inconsistency (I-square) $=0.0 \%$

Morgan et al. ${ }^{7}$
Killick et al ${ }^{13}$

Diagnostic OR $(95 \mathrm{Cl})$

$14.46(6.79-30.80)$

$16.67(6.37-43.62)$

Fixed effects model

Pooled diagnostic odds ratio $=15.08$ (8.43 to 26.98)

Cochran- $\mathrm{Q}=0.05 ; \mathrm{df}=1 \quad \mathrm{p}=0.8176)$

Inconsistency (I-square) $=0.0 \%$

FIGURE 3 Florest plot showing of sensitivity (A), specificity (B) and odds ratio diagnostic (C). 
and meta-analysis to specifically investigate and compare EN2 as a possible biomarker for PCa.

According to Pandha et al., ${ }^{14}$ EN2 test can lead to faster diagnosis, saving thousands of lives, and has the potential to reduce the cost of disease. However, it has the disadvantage of not providing disease progression or predicting tumor recurrence.

To date, the PSA is the most widely used tumor biomarker to detect, track and monitor PCa. In the literature, there are still differences regarding the use of PSA indicative of biopsy to confirm cancer. There is a lack of consensus among the authors on the ideal point. This contributes substantially to the great heterogeneity between the studies. ${ }^{15}$

Interestingly, there are few published studies assessing EN2 protein in PCa because it is a relatively new subject. It is thus necessary to conduct further studies so that we can understand the actual link between the EN2 protein and $\mathrm{PCa}$, as well as in other types of neoplasias, such as breast cancer. Certainly, the development of new studies on this subject is essential to come up with a fast, accurate and primary diagnosis in cancer evaluation.

Considering the high specificity of EN2 and the high sensitivity of PSA, we hypothesize that using both tests together would increase the likelihood of PCa diagnosis. Thus, we suggest future studies to investigate if this occurs in the practice.

We used the GRADE approach to assess the quality of the evidence produced in this study, classifying it as low, which means that "further research is very likely to have an important impact on our confidence in the estimate of effect and is likely to change the estimate or any estimate of effect is very uncertain." The evidence was downgraded due to risk of bias (limitations in the study design and execution) and indirectness (differences in patients, time and flow of tests) across the included studies.

A limitation of this study is that some of the included control patients did not undergo prostate biopsy. The study protocol includes annual PSA screening for 5 years, at which point recruits are offered an optional prostate biopsy; approximately half of the 392 individuals with PSA $3.0 \mathrm{ng} / \mathrm{mL}$ will undergo prostate biopsy. However, we decided to include this study because all PCa patients included were diagnosed by biopsy and did not present heterogeneity between the studies.

\section{Conclusion}

The low sensitivity and high specificity must be analyzed carefully, since there are few studies analyzing EN2 and the quality of evidence is low. It is too early to recommend EN2 for detection and/or screening of PCa.

\section{Conflict of interest}

The authors declare no conflict of interest.

\section{Resumo}

Proteína EN2 urinária no diagnóstico do câncer de próstata: revisão sistemática e metanálise

Introdução: $\mathrm{O}$ câncer de próstata é o segundo tipo de câncer diagnosticado e a quinta causa de morte em homens em todo o mundo. O diagnóstico precoce é fundamental para o prognóstico da doença. Atualmente, o antígeno específico da próstata (PSA) é o biomarcador mais utilizado; porém, biomarcadores mais específicos devem ser estudados.

Objetivo: Avaliar a acurácia da proteína engrenada-2 (EN2) na urina como biomarcador de câncer de próstata.

Método: Foi realizada uma busca abrangente no período de janeiro de 2005 a julho de 2016, utilizando as seguintes bases de dados eletrônicas: Medline (PubMed), Embase, Cochrane Library e Lilacs. As palavras-chave utilizadas foram: "engrailed-2", "EN2", "prostatic neoplasms". A busca foi limitada a humanos e não houve restrição de idioma. A avaliação da qualidade dos estudos incluídos foi realizada de acordo com Quadas-2. A análise estatística foi realizada usando o software Meta-DiSc® e RevMan 5.3.

Resultados: Foram identificados 248 estudos. Após a triagem dos títulos e resumos, foram excluídos 231. Um total de 17 foram lidos na íntegra e dois, incluídos na metanálise. A sensibilidade combinada foi de 66\% (IC95\% 0,56-0,75). A especificidade foi de 89\% (IC95\% 0,86-0,92). O DOR foi de 15,08 (IC95\% 8,43-26,97).

Conclusão: O teste EN2 mostrou alta especificidade (89\%) e baixa sensibilidade (66\%).

Palavras-chave: câncer de próstata, biomarcador, EN2, revisão sistemática, metanálise.

\section{References}

1. Siegel RL, Miller KD, Jemal A. Cancer statistics, 2015. CA Cancer J Clin. 2015; 65(1):5-29.

2. Humphrey PA. Gleason grading and prognostic factors in carcinoma of the prostate. Mod Pathol. 2004; 17(3):292-306

3. Sarkar S, Das S. A review of imaging methods for prostate cancer detection. Biomed Eng Comput Biol. 2016; 7(Suppl 1):1-15

4. Shao YH, Demissie K, Shih W, Mehta AR, Stein MN, Roberts CB, et al. Contemporary risk profile of prostate cancer in the United States. J Natl Cancer Inst. 2009; 101(18):1280-3. 
5. Ilic D, Neuberger MM, Djulbegovic M, Dahm P. Screening for prostate cancer. Cochrane Database Syst Rev. 2013; (1):CD004720.

6. Hugosson J, Carlsson S, Aus G, Bergdahl S, Khatami A, Lodding P, et al. Mortality results from the Göteborg randomised population-based prostatecancer screening trial. Lancet Oncol. 2010; 11(8):725-32.

7. Morgan R, Boxall A, Bhatt A, Bailey M, Hindley R, Langley S, et al. Engrailed-2 (EN2): a tumor specific urinary biomarker for the early diagnosis of prostate cancer. Clin Cancer Res. 2011; 17(5):1090-8.

8. Liberati A, Altman DG, Tetzlaff J, Mulrow C, Gøtzsche PC, Ioannidis JP, et al. The PRISMA statement for reporting systematic reviews and meta-analysis of studies that evaluate healthcare interventions: explanation and elaboration. BMJ. 2009; 339:b2700.

9. Whiting PF, Rutjes AW, Westwood ME, Mallett S, Deeks JJ, Reitsma JB, et al.; Quadas-2 Group. Quadas-2: a revised tool for the quality assessment of diagnostic accuracy studies. Ann Intern Med. 2011; 155(8):52936 .
10. Altman DG. Some common problems in medical research. In: Altman DG, editor. Practical statistics for medical research. 9. ed. London: Chapman; 1999. p. 396-439.

11. Review Manager (RevMan) [Computer program]. Version 5.3. Copenhagen: The Nordic Cochrane Centre, The Cochrane Collaboration.

12. Zamora J, Abraira V, Muriel A, Khan KS, Coomarasamy A. Meta-DiSc: a software for meta-analysis of test accuracy data. BMC Med Res Methodol. 2006; 6:31.

13. Killick E, Morgan R, Launchbury F, Bancroft E, Page E, Castro E, et al. Role of Engrailed-2 (EN2) as a prostate cancer detection biomarker in genetically high risk men. Sci Rep. 2013; 3:2059.

14. Pandha $\mathrm{H}$, Sorensen KD, Orntoft TF, Langley S, Hoyer S, Borre M, et al. Urinary engrailed-2 (EN2) levels predict tumour volume in men undergoing radical prostatectomy for prostate cancer. BJU Int. 2012; 110(6 Pt B ):287-92.

15. Santos CL, Lamounier TAC. Aspectos clínicos e laboratoriais do câncer de próstata [final paper]. Brasília: Curso de Biomedicina; Universidade Católica de Brasília; 2013. 